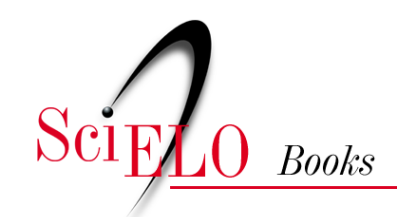

\title{
7. Literatura juvenil brasileira \\ espaço e representação social em acervo do PNBE
}

Mirian Hisae Yaegashi Zappone

\section{SciELO Books / SciELO Livros / SciELO Libros}

ZAPPONE, M.H.Y. Literatura juvenil brasileira: espaço e representação social em acervo do PNBE. In: SILVA, M.C., and BERTOLETTI, E.N.M., orgs. Literatura, leitura e educação (online). Rio de Janeiro: EDUERJ, 2017, pp. 181-205. Pesquisa em educação/ Práticas de leitura e escrita series. ISBN 978-85-7511-497-1. Available from: doi: 10.7476/9788575114971.0008. Also available in ePUB from: http://books.scielo.org/id/5gg44/epub/silva-9788575114971.epub

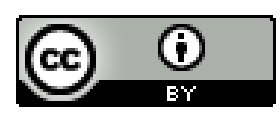

All the contents of this work, except where otherwise noted, is licensed under a Creative Commons Attribution 4.0 International license.

Todo o conteúdo deste trabalho, exceto quando houver ressalva, é publicado sob a licença Creative Commons Atribição 4.0.

Todo el contenido de esta obra, excepto donde se indique lo contrario, está bajo licencia de la licencia $\underline{\text { Creative Commons }}$ Reconocimento 4.0. 


\section{7 \\ Literatura juvenil brasileira: espaço e representação social em acervo do PNBE $^{1}$}

Mirian Hisae Yaegashi Zappone

\section{I Problematizando a representaçáo na literatura brasileira: duas pesquisas}

Em 1985, Fúlvia Rosemberg publicava Literatura infantil $e$ ideologia, texto no qual apresentava resultados de uma pesquisa analisando 168 livros infantojuvenis brasileiros editados ou reeditados entre os anos de 1955 e 1975 e que circulavam no mercado editorial brasileiro. Recorrendo a uma abordagem quali-quantitativa, a pesquisadora tinha por objetivo estudar a relação entre adultos e crianças, examinando a bipolarização dominador-dominado a partir da observação de categorias relacionadas a idade, sexo, cor e etnia dos personagens dos livros. Suas unidades de análise foram as personagens presentes na ilustração, no texto e em seus comportamentos.

Os achados de Rosemberg (I985) figuraram, na década de I980, como um dos primeiros panoramas sobre representação social da literatura infantojuvenil. A partir de dados qualitativos, a autora observou que, na esfera da produção, a maior parte dos agentes eram homens atuando como autores, ilustradores ou diagramadores. Do total de narrativas, observou que 90\% delas haviam sido produzidas no eixo Rio-São Paulo, evidenciando

I Este texto foi publicado na revista Teias, v. I6, n. 4I (20I5), e adaptado para este livro. 
que os maiores centros tendem a "impor os produtos culturais que lhes são específicos a outras populações que possuem traços próprios, fazendo eclodir, ou mesmo destruindo suas peculiaridades" (p. 46). Quanto à autoria, verificou-se que era frequentemente masculina (78\% autores versus $28 \%$ autoras), com predominância de autores maduros (com idades entre 40 a 59 anos), nascidos antes de 1920 .

$\mathrm{Na}$ análise das personagens, outros pontos chamaram a atenção: as mulheres eram minoria dentro das histórias e apareciam, quase sempre, como coadjuvantes, pois as aventuras eram frequentemente vivenciadas por meninos. Sobre a cor e a raça das personagens, a autora chama a atenção para as estratégias discriminatórias e veladas que estavam presentes nas narrativas estudadas e sobre a discriminação sofrida por grupos minoritários como negros e índios.

Chamava a atenção o caráter modelar da maioria das personagens que atuavam no sentido de construir uma narrativa didatizante em que o maniqueísmo da equação bem versus mal servia à pedagogia do exemplo aos leitores em formação. Por isso, temas como sexo ou morte não apareceram nas histórias estudadas. $\mathrm{O}$ panorama apresentado pela autora evidenciava, naquele momento, o pouco prestígio da produçáo literária voltada à infância e à juventude quando ainda não se via nela o grande filão mercadológico em que se transformaria ao longo das décadas de i980 e I990, alavancado, no século XXI, pelas compras governamentais.

Anos depois, outro estudo de caráter quali-quantitativo seria realizado por Regina Dalcastagnè, tendo, entretanto, como corpus investigativo, o romance brasileiro contemporâneo. Também com o objetivo de estudar a personagem, a pesquisa de Dalcastagnè abarcou 285 romances publicados por casas editorais representativas no campo literário brasileiro, produzidos no período de 1994 a 2009. Essa pesquisa resultou no levantamento de I.245 persona- 
gens - aquelas de importância maior na trama, sem, contudo, reduzir-se às protagonistas.

Embora as duas pesquisas possuam um intervalo temporal de mais de 30 anos, os resultados encontrados apresentam muito mais semelhanças do que diferenças. Segundo Dalcastagnè (2007), a produção literária continua a ser uma atividade predominantemente masculina, pois a autoria feminina não chega a $30 \%$, contra os $72,7 \%$ de autoria masculina. Além da homogeneidade em relação ao gênero, chama a atenção o fato de 93,3\% dos autores serem brancos e com escolarização superior, além de estarem estabelecidos, quase todos (90,3\%), nas grandes capitais.

Em relação às narrativas, Dalcastagnè (2007) mostra que o espaço das histórias é frequentemente a metrópole $(82,6 \%)$, em detrimento dos espaços rurais (I4,3\%) e das cidades médias (37,2\%). Quanto ao sexo, houve predominância de personagens masculinos $(62,1 \%)$ contra apenas $37,8 \%$ de personagens femininos. Quando esses dados são analisados em relação à posição dos sexos na narrativa, fica evidente a maior importância dispensada aos personagens masculinos: 71,1\% dos protagonistas são homens e apenas $28,9 \%$, mulheres. Com relação à orientação sexual, ou seja, "à direção do desejo da personagem" (p. I7), a heterossexualidade foi maciça, abarcando $8 \mathrm{I} \%$ dos personagens, sendo a homossexualidade observada apenas em 3,9\% dos casos.

Em relação à cor da personagem no romance brasileiro contemporâneo, $79,8 \%$ dos personagens sáo brancos, $7,9 \%$, negros, 6,I\%, mestiços e I, $2 \%$ indígenas, evidenciando uma presença muito pequena das comunidades não brancas, muito embora, no Brasil, sejam a maioria.

Esses dados são apresentados aqui não apenas por inventariar pesquisas quali-quantitativas sobre a literatura brasileira, mas também pelos achados que nelas problematizam uma questão ainda maior: a da representação. Na pluralidade das representa- 
ções de mundos e de seres, a literatura pode preencher nossa necessidade de ficção e levar, como aponta Candido (1992), a um conhecimento do mundo e do ser ao representá-los na forma de um romance, por exemplo. Entretanto, a palavra representação, tanto no caso da literatura juvenil como no da literatura em geral, deve ser aqui problematizada. Representar, segundo o Dicionário Aurélio, significa "ser a imagem ou a reprodução de" (Ferreira, I995, p. 564), significado semelhante ao do termo imitação, referido por Aristóteles ao comentar, em sua Poética, a natureza das composiçôes literárias. Para esse pensador, o traço distintivo das composiçóes literárias seria o modo pelo qual patrocinavam a imitação das coisas ou sua representação (Aristóteles, I98I, p. I9). Assim, a literatura imita a realidade, representando, por meio de figuraçôes miméticas distintas, os diversos elementos de tal realidade - espaço, tempo, pessoas, situaçóes, modos de pensar e de conceber a realidade etc.

A crítica literária esteve, por bastante tempo, ocupada exatamente com os modos da imitação, ou seja, com as diferentes técnicas empregadas pelos autores para criar suas obras. Assim, o grande tema dos estudos literários foi a descrição dos procedimentos de criação literária, ou seja, os modos de representação ou de imitação que a literatura efetuava. Em poucas situaçôes, houve preocupação com os seres, situaçóes ou realidades representados nos livros e romances. No entanto, uma questáo que se apresenta para a crítica literária e que, neste texto, revela-se como um problema de pesquisa não é apenas a estético ser pensada em termos de parâmetros distintos, mas também em que medida a literatura, especialmente a literatura juvenil brasileira, tem conseguido representar as diferentes realidades e os diferentes grupos sociais que configuram a sociedade brasileira. Sobre essa questão, Dalcastagnè (2008) pondera: "O que se coloca hoje não é simplesmente o fato de que a literatura fornece determinadas representaçóes da 
realidade, mas sim que essas representaçôes não são representativas do conjunto das perspectivas sociais" (p. 4).

Essa preocupação parece ser bastante pertinente quando cotejamos as pesquisas de Rosemberg (1985) e Dalcastagnè (2008), em que se desenham os mesmos cenários: um mundo urbano com mais proeminência de homens do que de mulheres, branco, de classe média e heterossexual, o que leva a inferir que o romance brasileiro, tanto o adulto como o juvenil, apresenta um recorte enviesado da sociedade, bastante atrelado à perspectiva de seus produtores.

De acordo com Chartier (1990), a representação é "instrumento de um conhecimento mediador que faz ver um objeto ausente através da substituição por uma imagem capaz de o reconstituir em memória e de o figurar como ele é" (p. Io). Assim, a coisa ou o ser representado revelam o modo como seu criador os vê. Segundo Compagnon (2006), para Aristóteles, a representação visava não ao estudo das relaçôes entre literatura e realidade, mas à ação, à produção da ficção poética verossímil. Portanto, a mimesis aristotélica, para o autor, "seria a representação de açôes humanas pela linguagem [...] e o que lhe interessa é o arranjo narrativo dos fatos em história" (p. IO4). Modernamente, os estudos da mimesis não a aceitam mais como uma simples cópia da realidade; ela constitui uma forma especial de conhecimento do mundo humano que inclui o tempo do reconhecimento. A mimesis, ou representação, passa a ser problematizada pela teoria literária de modo a se dispensar atenção à realidade, ao referente construído por aquele que produz a obra literária e também ao modo como os públicos podem conceder-lhe significados.

Representar em literatura é, entáo, criar um mundo segundo a ótica do criador e, portanto, também "falar em nome do outro", como salienta Dalcastagnè. Ao se manifestar pelo outro, o discurso de um interlocutor acaba por legitimar a presença daquele com 
maior competência, o que causa, na maioria das vezes, o silêncio de quem é representado. Apenas o discurso com reconhecimento social acaba por ter valor. De acordo com Dalcastagnè (2008), em geral, na imposição de um discurso, a legitimação acontece em razão da justificativa do maior esclarecimento, da maior eficácia social deste sobre o outro, sobre aquele que é silenciado. Com relação à representação, ainda segundo a pesquisadora, uma única forma de olhar a sociedade pode não representar, de modo condizente, os diferentes grupos que a formam. Surge, assim, a questáo da legitimidade: quando um texto literário ou qualquer outra manifestação simbólica representam um grupo ou um indivíduo por formas socialmente reconhecidas, as identidades desses grupos e indivíduos passam a ser legitimadas: ou seja, a representação não só patrocina a mímese, como também ajuda a constituir a própria realidade - afinal, a linguagem constrói o mundo. Por essa razão, é importante discutir a ausência ou a presença de determinados grupos sociais nas expressóes artísticas, especialmente de textos literários que podem circular na escola, tais como aqueles dos acervos do Programa Nacional Biblioteca na Escola (PNBE).

Numa sociedade multifacetada por traços raciais, por diferentes condiçôes econômicas, por crenças religiosas plurais e outros, cabe problematizar levando em conta o valor da literatura juvenil brasileira como bem cultural significativo na formação de leitores. Além disso, é preciso efetuar um levantamento sobre como as narrativas da literatura juvenil brasileira contemporânea lida e difundida na e pela escola têm efetuado a representação dos grupos sociais que compóem nossas cultura e população, e sobre as implicaçóes dessa representação no caso da formação de leitores que recebem essa literatura como um conjunto de textos de valor, mas com o qual, muitas vezes, pode não se identificar ou se identificar muito pouco. 


\subsection{Delineando o corpus da pesquisa: literatura juvenil e o PNBE}

Em 1997, o Fundo Nacional de Desenvolvimento da Educação (FNDE) criou o Programa Nacional Biblioteca na Escola (PNBE), como uma das açôes da política de fomento da leitura elaboradas pelo Ministério da Educação. Tendo em vista a baixa posse de livros nos lares brasileiros e as poucas bibliotecas escolares e públicas, como demonstram pesquisas como "Retratos da leitura” (Instituto Pró-Livro, 20II; 20I3), o programa tem por objetivo o acesso da comunidade escolar e náo escolar à informação e à cultura, seja por meio de acervos de obras de referência, seja de obras para a formação de professores, seja ainda de periódicos e de obras de literatura em geral. Anualmente, por meio de portaria ministerial, um colegiado formado por representantes do Conselho Nacional de Secretários da Educação, da União Nacional de Dirigentes Municipais de Educação (Undime), do Programa Nacional de Incentivo à Leitura (Proler), de intelectuais e de especialistas das áreas de leitura, literatura e educação de universidades públicas e do Ministério da Educação atua para avaliar as obras inscritas no programa. Após essa avaliação, que abarca quesitos como qualidade gráfico-editorial, material, estética e temática das obras, são divulgadas as listas com as obras selecionadas para o programa e que seráo enviadas às escolas.

Por sua consistência e duração, o PNBE se configura como uma das mais bem organizadas políticas de incentivo à leitura, ao menos em termos operacionais, levando-se em conta que náo existem estatísticas no site do FNDE sobre a real apropriação dos textos pelos alunos, e poucos são os estudos realizados sobre sua recepção nas escolas, seja por parte de professores, seja por parte de alunos. Chamam a atenção os números e as cifras do programa, que procura atender escolas brasileiras de ensino básico, ge- 
rando cifras que chegam a milhóes. Os dados dos últimos quatro anos do programa ${ }^{2}$ apontam que os anos finais da educaçáo básica foram contemplados com acervos literários, respectivamente, em 2OII e 20I3. Especificamente em 20I3, foram adquiridos mais de cinco milhôes de livros distribuídos em 50.556 escolas do ensino fundamental. Embora seja um programa dispendioso, o PNBE se consolidou, ao longo dos anos de sua execução, como política de Estado, por uma razão especialmente significativa: sua abrangência junto ao público visado - alunos de todas as escolas brasileiras do ensino básico.

Ao considerar a noção de campo literário, tal como Bordieu (20I3) formula, como espaço simbólico em que atuam crítica acadêmica, autores, público e demais instâncias mediadoras (editores, editoras, agentes literários etc.), compondo um campo de força que visa ao reconhecimento e ao prestígio - campo no qual seja possível assegurar não apenas suas predileçóes artísticas e seu conjunto de valores, como também o próprio direito de manifestá-las na qualidade de autoridade competente para tanto -, não seria impertinente considerar o PNBE uma instância de legitimação significativa no contexto de um subcampo da literatura juvenil brasileira.

Por essa razão, ao se pensar no problema da valoração na literatura juvenil contemporânea, os acervos de literatura do PNBE passam a ter um caráter bastante representativo, já que sua seleção é duplamente avalizada: tem a fiança da academia, pois os avaliadores das obras são professores universitários especialistas na área e, ao mesmo tempo, recebe a chancela governamental, como um patrimônio cultural digno de figurar como "clássico", ou seja, bem cultural que pode circular na classe, na sala de aula.

2 Os dados específicos sobre a quantidade de livros adquiridos, escolas beneficiadas e valores investidos podem ser encontrados em: <http://www.fnde.gov.br/programas/biblioteca-da-escola/biblioteca-da-escola-dados-estatisticos $>$. Acesso em I2 maio 2015 . 
Considerando, pois, a importância dos acervos do PNBE no campo literário em que se circunscreve a literatura infantil e juvenil, objetivou-se realizar, em moldes similares ao das pesquisas de Rosemberg (1985) e de Dalcastagnè (2008), um estudo sobre os personagens da literatura juvenil contemporânea, com vistas a verificar, de modo diacrônico, como são representados os personagens. Nesse sentido, selecionou-se para o corpus o acervo PNBE 2013 destinado aos anos finais do ensino fundamental, por ser o acervo mais recente de obras literárias e por abarcar textos voltados ao público juvenil. Tal acervo contava com I8o textos, dos quais foram selecionadas apenas as narrativas longas (novelas ou romances), uma vez que havia outros gêneros (poesia, quadrinhos, biografias, memórias, contos e novelas).

Feita a seleção do corpus, foram totalizados 56 textos contemporâneos, todos produzidos a partir de $1980^{3}$ e estudados tomando por base uma metodologia quali-quantitativa, com a confecção de fichas para os personagens proeminentes, o que resultou num total de 235 personagens, todos analisados conforme a metodologia proposta por Dalcastagnè $(2007,2008) .{ }^{4}$

3 Adotamos a proposiçấo de Ceccantini (2000), no sentido de considerar contemporânea a produção realizada a partir de I980, não só por seu aspecto literário, mas também por coincidir com um momento histórico significativo na história brasileira: a derrubada do regime militar.

4 Ressaltamos que essa metodologia foi elaborada por Regina Dalcastagnè e aplicada, inicialmente, a romances da literatura brasileira contemporânea. Em seus trabalhos, a pesquisadora elabora questionários aplicados a personagens proeminentes, cujos dados são submetidos ao software Sphinx Léxica 5.o, que possibilita sua tabulação e seu cruzamento. Em função da importância das pesquisas de Dalcastagnè no contexto dos estudos da literatura brasileira contemporânea, bem como por sua contribuição metodológica para estudos que visam a levantamentos, valemo-nos, neste projeto, dos mesmos instrumentos de pesquisa por ela elaborados. Cf. Dalcastagne, 2007, pp. I-38. Disponível em: < http://cronopios.com.br/anexos/regina_dalcastagne.swf >. Acesso em O2/03/2OI2. 


\subsection{Narrativa juvenil contemporânea no acervo PNBE 20I3 e os contornos da cidade}

Entre as 56 narrativas estudadas, um dado que inicialmente chamou a atenção foi o aumento significativo da autoria feminina: diferentemente do panorama observado por Rosemberg, em 1985, 42,8\% dos textos do corpus foram produzidos por mulheres e $57,2 \%$, por homens. Embora ainda se note uma atuação mais efetiva dos homens, houve um crescimento significativo da autoria feminina, da ordem de quase $50 \%$, se compararmos esses dados com os da década de 1980 e até mesmo com as pesquisas de Dalcastagnè (2008) sobre o romance brasileiro contemporâneo, em que a autoria feminina representa apenas $27,2 \%$. Assim, no corpus observa-se uma visibilidade maior da produçáo literária de mulheres.

No que diz respeito ao tempo das histórias narradas, $60,7 \%$ delas foram ambientadas no contexto contemporâneo, ou seja, da década de 1980 aos dias atuais. Dez delas situaram-se em outros períodos históricos (notadamente no passado, como Atrás do paraiso, de Ivan Jaff, ou Sortes de Villamor, de Nilma Lacerda); oito, em períodos indefinidos; e quatro abarcaram o período da ditadura militar ( $O$ gênio do crime, de João Carlos Marinho; $O$ Golem do Bom Retiro, de Mário Teixeira; Quarto de despejo, de Carolina Maria de Jesus, e Anita Garibaldi, a estrela da tempestade, de Heloísa Prieto).

É interessante observar que a literatura juvenil brasileira do corpus opta pelo presente como tempo a ser representado, o que sinaliza uma preferência pela representação do universo circundante do leitor e pode facilitar não apenas o trato com a linguagem, mas também a apresentação de temáticas e problemas da vida contemporânea, como os conflitos emocionais de adolescentes diante dos dramas familiares e sociais, a exemplo de textos 
como A distância das coisas, de Flávio Carneiro, Um na estrada, de Caio Ritter, Jogo da memória, de Laura Bergalo, ou A mocinha do mercado central, de Stella Maris Rezende.

Nesse sentido, embora a tematização de tempos longínquos e indefinidos seja característica da literatura infantojuvenil, que está associada ao uso da fantasia, notou-se, no corpus estudado, maior prevalência de textos que preferem uma abordagem mais realista ao uso da fantasia. Assim, os textos distanciaram-se, por exemplo, do que observou Colomer ${ }^{5}$ (2003) sobre a literatura infantojuvenil contemporânea espanhola, tipicamente marcada pelo uso da fantasia (seja por meio do uso de animais humanizados, seja por meio de outros recursos) em detrimento da ficção realista, que, no corpus da autora, representou apenas $18,4 \%$.

As histórias contadas no corpus acontecem, em sua maioria, nas regióes Sudeste e Sul do Brasil, com 3I ocorrências ao todo, abarcando 55,3\% das histórias; Nordeste, seis ocorrências; Centro-Oeste, duas; e Norte, nenhuma. Esses últimos são cenários bem menos explorados, sendo suplantados até mesmo pela ambientação em regiốes estrangeiras (I4 ocorrências). Tal homogeneidade no trato da representação geográfica dos espaços das histórias pode, em parte, ser explicada pela inserção geográfica dos escritores brasileiros, que, em sua maioria, como demonstraram os estudos de Dalcastagnè (2008), concentram-se no Rio de Janeiro, em São Paulo, no Rio Grande do Sul e em Minas Gerais, o que faz com que suas histórias tendam a retratar essas regióes. Por se tratar de uma questáo sintomática, essa representação do espaço geográfico aponta para uma homogeneidade nada desejável na

\footnotetext{
5 Teresa Colomer (2003) realizou uma pesquisa sobre a literatura infantojuvenil espanhola, observando suas características constitutivas (em um recorte estruturalista) e suas temáticas. Para tanto, selecionou um conjunto de mais de mil títulos entre três seleçôes institucionais, a partir das quais procedeu "à escolha das obras que eram mais citadas nas listas de seleçôes ou que tinham obtido mais prêmios", o que resultou em um total de II8 títulos.
} 
caracterização do espaço na literatura juvenil, sobretudo no Brasil, onde as distinçôes culturais, linguísticas, sociais e geográficas são ricas e plurais.

Ainda reflexo da inserção de seus autores, as narrativas do corpus evidenciaram a proeminência dos espaços de grande porte com destaque para a cidade grande - e de médio porte. Contrariando certa tradição da literatura infantojuvenil brasileira, que, até aproximadamente a década de 1950, centrava suas histórias no campo ou em espaços fantásticos e maravilhosos, como assinalaram Zilberman e Lajolo (I985), a literatura juvenil contemporânea, seguindo o ritmo do desenvolvimento pós-industrial, adotou a cidade grande como locus privilegiado. Tratando-se de um aspecto importante para a construção das histórias, é preciso demarcar que a espacialidade não se restringe à caracterização geográfica ou arquitetônica do espaço; ela é também um vetor da cultura, que nela se instala e nela se refrata. Por essa razão, a espacialidade ganha um caráter social e também político mais amplo, o que, no caso do corpus estudado, parece fazer muito sentido, pois é um dos elementos que podem conter a chave de explicação do mundo representado nas narrativas, uma vez que nelas se observa a hegemonia cultural da cidade, nos moldes destacados por Fortuna e Silva (20II):

As cidades, desde então [desenvolvimento da industrialização], não apenas assistiram ao adensamento da residência, dos locais de oferta de trabalho e de consumo, como, concomitantemente, sofreram profundas alteraçôes nas condições e modos de vida social, política e institucional que albergam. Estas alteraçóes autorizam que caracterizemos o século XX como o tempo de consumação de um processo longo de urbanizaçáo da cultura, que traduz e consagra a plena hegemonia da cultura gerada nas cidades face a outras expressóes culturais não urbanas (pp. 43I-2). 
Entre as narrativas estudadas, $57 \%$ foram ambientadas em espaços urbanos de grande porte, $25 \%$ em espaços urbanos de médio porte, restando $25 \%$ para espaços campestres e pouco mais de I $4 \%$ para narrativas em espaços fantásticos/maravilhosos e de pequeno porte. Nota-se, pois, de modo efetivo, uma representação, nas narrativas estudadas, da hegemonia cultural dos grandes centros urbanos, fruto do desenvolvimento pós-industrial de molde liberal, fato já observado na literatura brasileira adulta, como alude Pechman (20I4) ao afirmar que "se constituiu entre nós essa literatura que fez da cidade, e mais do que isso, da experiência urbana e, até mais ainda, da convivialidade na cidade, o palco, o sujeito e o objeto de sua criação" (p. 90).

Como já assinalado, a espacialidade apresenta um traço cultural, sendo demarcada por questóes políticas e sociais. Refletindo sobre aos traços sociais presentes no corpus, observou-se que a hegemonia cultural da cidade consistir em um dado explicativo quando se analisa o estrato socioeconômico dos personagens. Conforme mostra a tabela a seguir, boa parte do universo humano pertence à classe média, que consiste em praticamente $50 \%$ das ocorrências, sendo minoritária a presença de pobres e da elite:

Tabela 7.I.

\begin{tabular}{lcc}
$\quad$ Estrato socioeconômico & Frequência. & \% \\
\hline Casse média & II 6 & $49.4 \%$ \\
\hline Elite & 45 & $\mathrm{I} 9.2 \%$ \\
\hline Pobre & 38 & $\mathrm{I} 6.2 \%$ \\
\hline Sem indício & 27 & $\mathrm{II} .5 \%$ \\
\hline Miserável & 4 & $\mathrm{I} .7 \%$ \\
\hline Mobilidade econômica ascendente & 4 & $\mathrm{I} .7 \%$ \\
\hline Náo resposta & $\mathrm{I}$ & $0.4 \%$ \\
\hline Mobilidade econômica descendente & $\mathrm{O}$ & $0.0 \%$ \\
\hline TOTAL OBS. & 235 & $\mathrm{I} \% 0$ \\
\hline
\end{tabular}

Fonte: Pesquisa Literatura juvenil contemporânea no acervo PNBE 2013: um estudo das representaçóes sociais, Universidade Estadual de Maringá. 
A presença maciça da classe média, longe de ser uma mera predileção dos autores ou mesmo de um aspecto de sua autorrepresentação, aparece nos textos como uma das consequências do processo de urbanização e do desenvolvimento econômico, o qual fez diminuir o contingente das classes minoritárias (ricos e pobres) $e$ ampliar os espaços da classe média, conferindo maior amplitude à sua cultura e a seu modus vivendi.

A moderna cultura urbana atenua as barreiras entre a "cultura do povo" e a "cultura de elite" que mantinham separadas e incomunicáveis as principais classes sociais do ancien régime. Em alternativa a esta polarização, gradualmente, assistiu-se à instauração de uma vida urbana, cultural e institucional mais agregadora e abrangente socialmente, de que ressalta o crescimento das classes médias que, neste contexto, ilustram uma espécie de convergência ao centro das classes sociais polares e das respectivas expressóes e produtos culturais típicos (Pechman, 20I4, p. 432).

Assim, o mundo representado nas narrativas é, sobretudo, o das classes intermediárias ou o da classe média brasileira $(76,6 \%$ dos personagens são brasileiros, contra apenas II, $9 \%$ de estrangeiros), cujo desenho familiar é fartamente apresentado. Afastando-se do sentido inicial de mero lugar da ação social ou da interação harmônica entre seus partícipes, o conceito de cidade, na contemporaneidade, deixa entrever fraturas, sobretudo aquelas ligadas ao modo como os sujeitos se movem nela: "a cidade é espaço do trânsito dos indivíduos que, influenciados pela lógica do capital, buscam a satisfação pessoal imediata de suas necessidades, valorizam o individualismo e a privacidade/domesticidade" (Fortuna, 20II, s.p.). É por essa razáo que grande parte das histórias narradas no corpus detém-se na construção de dramas pessoais, vivenciados a partir do núcleo familiar, numa espécie de fechamento do mun- 
do privado, fazendo crer como verdadeira, para essas narrativas, a afirmação de Pechman, no sentido de que "os atuais personagens da ficção urbana parecem completamente descompromissados com a cidade, e todo o caudal de urbanidade e sociabilidade que ela induz" (Idem, p. 9I). Nesse sentido, é sintomático constatar que o espaço restrito mais frequentado pelos personagens é o doméstico $(79,2 \%)$, com $50 \%$ a mais de ocorrências do que o segundo espaço mais frequentado - ruas e praças $(37 \%)$-, seguido de mata/campo/floresta (26\%), o que leva a se inferir que há uma de retração do espaço público e a consequente ampliaçáo do privado nas narrativas.

Entre os temas trabalhados nas 56 narrativas, observou-se a recorrência de alguns que foram englobados nas seguintes categorias: temas sociais (sete ocorrências), tais como preconceito racial, vida de classes pobres e miseráveis, disputa pela terra, processos de urbanização; temas familiares (dez ocorrências), como relacionamento entre pai e filho, relacionamento familiar, relação entre avô e neto, vivência conflituosa na família, novas configuraçôes familiares; temas do universo adolescente (com I5 ocorrências), em que se abordam, basicamente, os relacionamentos amorosos, o amadurecimento emocional do jovem e os conflitos familiares na adolescência. Além desses três temas, foram encontrados outros temas isolados: temas policiais ou detetivescos (cinco), leitura como processo criativo, história do Brasil, história das grandes navegaçóes, de quilombos e biografia romanceada.

Se a cidade grande é o espaço privilegiado nas narrativas estudadas, com sua arquitetura, suas ruas e suas praças, ou seja, a corporeidade material da cidade, ela cede lugar para a espacialidade social: é o local em que transitam grupos sociais específicos, entre os quais se destacam, no corpus estudado, o universo adolescente da classe média, cujo mundo circundante mais próximo é a família e, eventualmente, a escola. 
Entre as histórias que envolvem, de modo mais enfático, o núcleo familiar, estão Jogo da memória, de Laura Bergallo, em que uma família de ascendência italiana, particularmente o garoto Lucca, precisa enfrentar a doença do avô, Pietro, que sofre de Alzheimer. Em meio à trama, sobressaem cenas como almoços em família e retomadas históricas da imigração da família de classe média, que, diante de sua limitação econômica, precisa cotizar-se para enviar o pai em viagem à Itália.

Ainda no ambiente familiar de classe média, situa-se a história de Pedro, um garoto de I4 anos que perde o pai e a mãe (professora de literatura), em $A$ distância das coisas, de Flávio Carneiro. Tutelado pelo tio, o garoto é proibido de visitar o túmulo da mãe, o que o leva a buscar respostas para o comportamento do tio, entrando, assim, em um processo de amadurecimento emocional.

Em Um sonho no caroço de abacate, de Moacyr Scliar, as famílias de Mardoqueu, um garoto judeu, e de Carlos, um jovem negro, passam a se relacionar, pondo em evidência questóes sobre preconceito e bullying na escola.

Em O mundo de Camila, de Márcia do Canto, a família constitui o núcleo dramático central, em que os novos arranjos familiares são apresentados pela narradora, a garota Camila, que convive com tios homossexuais, pais divorciados e meios-irmãos.

Retratando ainda aspectos da família de classe média de um modo menos ou mais enfático, elencam-se as narrativas Tá falando grego, de Ricardo Hofstetter, Antes que o mundo acabe, de Marcelo Carneiro da Cunha, Isso ninguém me tira, de Ana Maria Machado, $O$ outro passo da dança e Um na estrada, ambos de Caio Riter, Pó de Parede, de Carol Bensimon, e O enigma de Iracema, de Rosana Rios.

Ainda atestando a centralidade da família nas tramas, destaca-se o fato de que os papéis afetivos desempenhados pelos personagens são os de filho (7I de 235 ocorrências), irmão/ã (22), mãe 
(20), pai (I8) ou parentes (I8), contrapondo-se personagens que náo integram as relaçóes familiares, como amigos (83), ou personagens sem nenhum vínculo familiar (34). Enfim, o que se nota é que, numa somatória, as relaçóes familiares aparecem em maior frequência (com 149 ocorrências) do que as relaçôes não familiares (II7).

Em meio à configuração social da cidade, que, no caso do corpus, é marcadamente familiar e de classe média, sobrelevam-se os dramas adolescentes. Fazendo coro com a tradição da literatura juvenil, em que se destacam as narrativas em forma de bildungsroman ou romances de formação, o universo adolescente é amplamente tematizado no corpus, de modo a ressaltar formas de aprendizado de vida e amadurecimento, favorecendo valores morais que se baseiam na compreensão das relaçóes humanas, na tolerância e na crença na resolução reflexiva dos conflitos pessoais. Essa centralidade da vida adolescente é atestada pelo número de personagens adolescentes/jovens presentes no corpus $(32,7 \%$, ou 77 ocorrências), superior ao de outras faixas etárias (adultos, 30,2\%, e crianças, $14,9 \%)$.

Com frequência, o drama adolescente se situa justamente em relação à família, seja pelas relaçôes difíceis com adultos problemáticos (alcoolismo, negligência, intransigência) ou pela falta dessas mesmas relaçóes, no caso de ausência ou abandono dos pais. São bons exemplos: Fala comigo, pai, de Júlio Emílio Braz; O outro passo da dança, de Caio Riter; A primeira vez que vi meu pai, de Márcia Leite; Pão feito em casa, de Rosana Rios; Um na estrada, de Caio Riter; e $A$ distância das coisas, de Flávio Carneiro. Em outros casos, associados aos problemas familiares, os adolescentes precisam superar conflitos internos gerados por situaçôes da própria vida e que os levarão a formas de maturação, como é o caso de Tuna, em Fala comigo, Pai; de Gabi, em Isso ninguém me tira; de Maria, em $A$ mocinha do mercado central; de Pedro, em 
A distância das coisas. Nesses textos, prevalece a ideia de que as pessoas podem avaliar seus problemas, verbalizá-los e buscar formas conciliatórias entre seus valores internos e o mundo circundante, perfazendo um caminho na direção da tolerância, da busca pela felicidade, da autonomia e da aceitação de si mesmo. A análise dos desfechos das narrativas corrobora essas afirmaçóes, já que 42,I\% dos personagens concluem sua trajetória numa situação de equilíbrio positivo, sendo que, analisadas essas situaçóes positivas, $24,7 \%$ referiam-se a resoluçóes de problemas/conflitos; $15,3 \%$, a conhecimento de si mesmo; e I3,6\%, a conhecimento de mundo.

Se o mundo retratado é o da cidade, focalizando a família de classe média e, nessa, a vida adolescente, o que é possível dizer sobre a cor e os gêneros representados no corpus? Certamente, trata-se de um mundo muito mais masculino do que feminino: das 235 personagens, 197 são homens e apenas 92 são mulheres. Muito embora se tenha observado no corpus aumento na autoria feminina, a questão dos gêneros ainda aponta para desigualdades: as mulheres carecem ainda de uma representação mais significativa, já que a presença dos homens é mais do que 50\% superior à de mulheres. Quando observados os papéis desempenhados na trama, o protagonismo masculino aparece em $60 \%$ dos casos dos 75 personagens que desempenharam papéis preponderantes, ao passo que os papéis femininos abarcam apenas $38 \%$.

A atuação feminina também aparece fragilizada quando se analisam as questôes de inserçáo no mundo do trabalho. Dos 63 personagens que têm trabalho formal, apenas $22(34,9 \%)$ são mulheres, enquanto quarenta $(63,5 \%)$ são homens. Essa representação oblíqua das relaçóes de gênero no mundo do trabalho pode ser observada nas profissóes mencionadas para homens e mulheres: foram arroladas 54 profissóes diferentes para homens e apenas i8 para mulheres, sendo que, no caso dos homens, as profissóes com maior ocorrência foram estudante, surfista, detetive, professor, ad- 
vogado, comerciante, empresário e agricultor, ocupaçôes de maior relevância social e econômica, ao passo que, no caso das mulheres, observaram-se profissóes de estudante, professora, dona de casa, aposentada, dona de pensão e escritora, fatos que evidenciam um imaginário sobre a mulher e sobre o trabalho realizado que muito se distancia da realidade social brasileira, na qual as mulheres não só têm maior escolaridade, como também representam um grande contingente de trabalhadoras em todos os campos.

Ainda no que diz respeito à discussão dos gêneros, é importante destacar que a pesquisa sobre a orientaçáo sexual das personagens apontou para a representaçáo maciça de uma afetividade heterossexual, com a ocorrência de apenas um caso de homoafetividade em personagem secundário, o que atesta que, mesmo em tempos de emergência de minorias, a literatura juvenil brasileira ainda vê os temas ligados à sexualidade como não apropriados aos leitores mirins, além de se alinhar a uma perspectiva ainda convencional e pouco problematizadora da questáo, o que também se comprova pelo fato de as práticas sexuais não serem mencionadas ou serem inexistentes ou até mesmo raras na vida dos personagens de todas as faixas etárias estudadas.

A homogeneidade da paisagem da grande cidade, que se descortina no corpus, contudo, não se refere apenas à preponderância do universo masculino em face às difíceis relaçóes de gênero, mas também à adoção de suas cores: $80 \%$ das personagens são brancas (I88 ocorrências), 22\% são pardos e amarelos (cinco), 7,2\% são negras (I7 ocorrências) e os índios são absolutamente ausentes. Tais dados evidenciam grandes lacunas no corpus estudado. Os personagens em que não foi possível inferir dados sobre a cor totalizam 9,8\%. Ao observar as questôes de pertença social, sexual, etária e étnica, os dados até aqui apresentados parecem contrapor-se à ideia de cidade moderna como locus de heterogeneidade e de 
disputas sociais e culturais, na perspectiva apontada por Fortuna e Silva (20II):

A cidade de hoje é marcada por uma cultura de fracturas e distâncias que a distingue de uma outra qualquer comunidade regida por princípios de partilha, comunhão de interesses e equidade social. Não se tratando de uma cultura de consagração da harmonia ou do consenso social, estipula condiçóes desiguais de acesso a direitos e revela uma cidadania disputada, objecto de conflitos sociais e políticos dispersos. Como qualquer entidade cuja unidade resulta da fragmentação dos seus elementos, a cidade e a cultura urbana são realidades incoerentes, recheadas de subcidades e subculturas (p. 432).

Ao elegerem o mundo da classe média e os conflitos adolescentes, predominantemente de homens brancos, heterossexuais e inseridos na grande metrópole, as narrativas tendem a uma representação homogênea da cidade contemporânea só ameaçada quando se observam as poucas exceçóes que refletem algumas das "fracturas" antes aludidas. Essas exceçóes é que tingirão de cores mais fortes as histórias e permitiráo que se matize a perspectiva social vivida das personagens, trazendo à tona, ainda que de um modo pouco recorrente, a cidadania disputada de que fala Fortuna.

Nesse sentido, é isso que se nota nos livros $O$ livreiro do Alemão, de Otávio Júnior, narrativa romanceada de um jovem negro que desenvolve um programa de estímulo à leitura na favela do Alemão, no Rio de Janeiro; em $O$ homão e o menininho, de Luís Pimentel, em que as relaçóes entre filhos e pais ou adultos e crianças extremamente pobres são descritas numa novela bem-humorada cujos elementos de continuidade, típicos do gênero, são exatamente os espaços de periferia e os personagens miseráveis; no excelente Quarto de despejo, de Carolina Maria de Jesus, e em sua 
história consagrada de uma mulher negra e favelada que se torna escritora; em Um sonho no caroço do abacate, de Moacyr Scliar, em que um jovem judeu de classe média se enamora de uma moça negra de elite; em Sortes de Villamor, de Nilma Lacerda, que narra a história da velha negra Ismê Catureba, que acolhia crianças negras órfẫs na Salvador do século XIX; ou no simbólico Tem um morcego no meu pombal, de Moisés Liporage, que fala do preconceito racial das famílias do morcego negro Samuca, que se apaixona pela pombinha branca Didi.

Essas "fracturas" também estão presentes nas relaçôes preconceituosas discutidas em $O$ golem do Bom Retiro, de Mário Teixeira, e na violência de $O$ outro passo da dança, de Caio Riter. Nessas narrativas, é possível ouvir, ainda que timidamente, as fraturas da hegemonia da classe média e os sussurros de algumas "subcidades" e suas "subcidadanias", habitadas, sobretudo, por negros, mulatos e pobres. Nesses textos, que náo ultrapassam $15 \%$ do corpus, o espaço urbano que se delineia é outro: favelas, ruas em que trabalham crianças vendedoras de miudezas e feiras livres, como em alguns episódios da novela $O$ homáo e o menininho:

De segunda a sábado o carrinho era o ganha-pão de Bidu, com ele fazendo carretos nas feiras-livres, transportando frutas, legumes, folhas e até peixes para os moradores das imediaçôes (Pimentel, 20IO, p. 7).

[...]

A menina estendeu a mão para o ônibus em Brás de Pina e entrou pela porta traseira [...]. Desceu na estaçẫo que fica ao lado do cinema e reabriu a caixa de goiabada no sinal. Vendia a vinte centavos cada; três por cinquenta (Idem, p. 25).

Também estáo presentes nos barracos de favela, desprovidos de cidadania, justiça, cultura, dignidade e dinheiro, mas cerca- 
dos por violência e insegurança, como em $O$ livreiro do Alemão, de Otávio Júnior, ou Quarto de Despejo, de Carolina Maria de Jesus:

Amanheceu chovendo. Tenho só treis (sic) cruzeiros porque emprestei 5 para Leila ir buscar a filha no hospital. Estou desorientada, sem saber o que iniciar. Quero escrever, quero trabalhar, quero lavar roupa. Estou com frio. E náo tenho sapato para calçar. Os sapatos dos meninos estão furados [...]. Todas as crianças de favela sabem como é corpo de uma mulher. Porque, quando os casais que se embriagam brigam, a mulher, para não apanhar, sai nua para a rua (Jesus, 20I3, p. 45).

Acho que poucos ouviram o primeiro tiro, mas o estampido me deixou preocupado. Os tiros foram se sucedendo e as crianças começaram a ficar apavoradas. Olhavam, assustadas, para os lados e pela janela (Júnior, 20II, p. IO).

[...]

Naquele mesmo dia, no começo da noite, uma chuva muito forte acabou com a luz no morro e em nossa casa. Minha mãe acendeu duas velas, o suficiente para iluminar o único cômodo que servia de sala, quarto e cozinha (Idem, p. 22).

Não fossem esses poucos livros dissonantes em relação à homogeneidade presente no corpus, a cidade grande, desenhada nas linhas das narrativas aqui estudadas, seria bem pouco plural em relação à representação da sociedade brasileira. Segundo Fortuna e Silva (20I4), "a cidade é sinônimo de heterogeneidade social e cultural, de relativização de perspectivas e de diversidade de estilos e de comportamentos sociais" (p. 423). Por ser arena de conflitos, a preservação dessas diferenças e das identidades variadas que podem emergir na cidade acaba sendo influenciada pela negociação e pelo contato com o diverso, o que pressupóe arranjos políticos, 
culturais e disputas pela cidadania. Entra-se, assim, no terreno do ideológico, em que a linguagem, sobretudo aquela do mundo letrado - a língua escrita -, constitui elemento de legitimação.

J. Culler (I999), ao discutir o aspecto performativo da linguagem a partir das teorias de J. L. Austin, afirma que a linguagem não é apenas referencial (representa ou nomeia coisas), mas também performativa, no sentido de criar a própria realidade, de fazer uma realidade existir: "Ela é performativa no sentido de que não apenas transmite informação, mas realiza atos através de sua repetição de práticas discursivas ou de maneiras de fazer as coisas estabelecidas" (p. 99). Por essa razão, para o autor, a literatura "não é uma pseudodeclaração frívola, mas assume seu lugar entre os atos de linguagem que transformam o mundo, criando as coisas que nomeia" (Idem, p. 97).

Ora, se a linguagem e, por extensão, a literatura (sobretudo os textos literários socialmente valorizados, como aqueles aqui discutidos) podem contribuir para a construçáo de diferente(s) realidade(s)/identidades, nada mais desejável que reflitam a pluralidade das perspectivas sociais, fazendo com que possam vir ao centro da cultura e da sociedade todos aqueles que ainda estáo nas margens, questionando, inclusive, as formas estereotipadas com que alguns grupos têm sido historicamente representados, tanto na literatura como no mundo das práticas sociais efetivas.

É evidente que náo se espera que a literatura, na qualidade de criaçáo do imaginário por meio do estético, seja mera cópia da realidade e dos seres. Se assim fosse, teriam valor para o leitor apenas os textos que falassem de sua vivência imediata. Tendo como uma de suas finalidades a expansão do universo cognitivo, emocional e social do jovem, a literatura juvenil brasileira contemporânea contribuiria com mais densidade para a emancipação do leitor na medida em que pudesse incorporar realidades múltiplas, confrontando a diversidade étnica, econômica, racial, sexual e so- 
cial que cerca o adolescente e que constitui o mundo urbano, no qual as sociedades contemporâneas, inescapavelmente, estão inseridas. Contribuiria, assim, para sua passagem ao universo adulto de uma forma que pudesse observar e talvez até mesmo questionar as amarras ideológicas com que o mundo por ele desejado - o dos adultos - tem sido construído.

\section{Referências}

ARISTÓTELES et al. A poética clássica. São Paulo: Cultrix, I98I.

CANDIDO, Antonio. "A personagem do romance". In ROSENFELD, A. et al. A personagem de fiç̧ão. São Paulo: Perspectiva, 1992.

CHARTIER, Roger. A história cultural. Rio de Janeiro: Bertrand, I990.

COLOMER, Teresa. A formação do leitor literário: literatura infantil e juvenil atual. Trad. de Laura Sandroni. São Paulo: Global, 2003.

COMPAGNON, Antoine. O demônio da teoria: literatura e senso comum. Belo Horizonte: UFMG, 2006.

CULLER, Jhonatan. "Linguagem performativa”. In Teoria literária: uma introdução. São Paulo: Beca Produções Culturais Ltda, 1999, pp. 95-Io6.

DALCASTAGNÈ, Regina. "A personagem do romance brasileiro contemporâneo: 1990-2004". Cronópios, pp. I-38, maio de 2007. Disponível em: $<$ http://cronopios.com.br/anexos/regina_dalcastagne.swf>. Acesso em o2 mar. 2012.

. "Vozes nas sombras: representação e legitimidade na narrativa contemporânea”. In Ver e imaginar o outro: alteridade, desigualdade, violência na literatura brasileira contemporânea. Vinhedo: Horizonte, 2008, pp. 78-I07.

FORTUNA, Carlos e SILVA, Augusto Santos. "A cidade do lado da cultura: espacialidades sociais e modalidades de intermediação cultural”. In SOUZA SANTOS, Boaventura (org.). A globalização e as ciências sociais. São Paulo: Cortez, 20II, pp. 419-68.

GOLDMANN, Lucien. Sociologia do romance. Trad. de Álvaro Cabral. São Paulo: Paz e Terra, I990. 
INSTITUTO PRÓ-LIVRO. "Fomento e acesso ao livro. Retratos da leitura (2OII, 20I3)”. Disponível em: http://prolivro.org.br/home/index.php/atuacao/25-projetos/pesquisas/39oo-pesquisa-retratos-da-leitura-no-brasil-48>. Acesso em 07 abr. 2015.

LAJOLO, Marisa e ZILBERMAN, Regina. Literatura infantil brasileira: histórias e histórias. São Paulo: Ática, 1985.

PECHMAN, Robert. "Desconstruindo a cidade: cenários para a nova literatura urbana”. In KUSTER, Eliana e PECHMAN, Robert (orgs.). O chamado da cidade: ensaios sobre a urbanidade. Belo Horizonte: Ed. da UFMG, 20I4, pp. 89-IOI.

ROSEMBERG, Fúlvia. Literatura infantil e ideologia. São Paulo: Global Editora, 1985 . 